\title{
PENGABDIAN KEPADA MASYARAKAT BANTUAN HIDUP DASAR PADA SANTRI
}

\author{
Ida Zuhroidah ${ }^{1 *}$, Mukhammad Toha ${ }^{2}$, Mokh. Sujarwadi $^{3}$, Nurul Huda ${ }^{4}$ \\ 1,2,3,4 Universitas Jember Kampus Kota Pasuruan \\ Email: ida.akper@unej.ac.id
}

\begin{abstract}
ABSTRAK
Angka kejadian henti jantung atau cardiac arrest ini berkisar 10 dari 100.000 orang normal yang berusia dibawah 35 tahun dan per tahunnya mencapai sekitar 300.000-350.000 kejadian. Pertolongan pertama yang tepat pada kasus henti jantung adalah bantuan hidup dasar (BHD). Tindakan yang bisa dilakukan adalah resusitasi jantung paru (RJP). Tujuan dari resusitasi jantung paru adalah mengembalikan sirkulasi spontan serta mempertahankan fungsi organ vital pada henti jantung dan henti nafas dengan melakukan kompresi dada dan bantuan nafas. Tujuan setelah dilakukan pelatihan ini diharapkan santri dapat berperan aktif dan dapat memberikan pertolongan pertama henti jantung dan henti nafas secara tepat serta mampu melakukan RJP. Kegiatan ini dilakukan dengan metode pemaparan teori tentang anatomi fisiologi sistem respirasi dan sistem sirkulasi, dampak dari henti nafas dan henti jantung, bantuan hidup dasar dan pada hari kedua dilanjutkan dengan praktik RJP melalui manekin. Hasil yang didapatkan sebagian besar santri (80\%) memahami dan mengerti tentang bantuan hidup dasar dan mampu mempraktekkan RJP kepada manekin meskipun masih butuh pendampingan.
\end{abstract}

Kata Kunci : bantuan hidup dasar, santri, pondok pesantren

\begin{abstract}
The incidence of cardiac arrest or cardiac arrest ranges from 10 out of 100,000 ordinary people aged under 35 years and annually reaches around 300,000350,000 events. Appropriate first aid in cases of cardiac arrest is basic life support (BLS). Action that can be done is cardiopulmonary resuscitation (CPR). Cardiopulmonary resuscitation aims to restore spontaneous circulation and maintain vital organ function in cardiac arrest and stop breathing by performing chest compressions and breath support. After this training, the goal is that students will be able to play an active role and be able to provide first aid for cardiac arrest and stopping breathing appropriately, and be able to perform CPR. This activity was carried out using the method of presenting theories on the respiratory system's physiological anatomy and the circulatory system, the impact of respiratory and cardiac arrest, basic life support, and on the second day, continued with the practice of CPR through mannequins. The results obtained were most of the students (80\%) understood and understood basic life support and were able to practice CPR to the mannequins even though they still needed assistance.
\end{abstract}

Keyword : basic life support, student, islamic boarding school 


\section{PENDAHULUAN}

Kegawatdaruratan adalah suatu keadaan seseorang yang berada pada suatu kondisi yang mengancam hidupnya dan memerlukan pertolongan pertama. Pertolongan pertama ini berguna untuk menghindari kecacatan dan kematian saat seseorang berada pada kondisi kegawatdaruratan. Kejadian gawat darurat dapat menimpa siapa saja dan terjadi dimana saja. Henti jantung adalah hilangnya fungsi jantung untuk memompa darah yang terjadi secara mendadak. Angka kejadian henti jantung atau cardiac arrest ini berkisar 10 dari 100.000 orang normal yang berusia dibawah 35 tahun dan per tahunnya mencapai sekitar 300.000-350.000 kejadian (PERKI, 2015).

Data dari Word Health Organization (WHO) Tahun 2019 penyakit kardiovaskuler adalah penyebab kematian nomer 1 di dunia, merenggut sekitar 17,9 juta jiwa setiap tahun. Empat dari kematian penyakit kardiovaskuler disebabkan karena serangan jantung dan stroke. Berdasarkan diagnosis dokter, prevalensi penyakit jantung koroner di Indonesia tahun 2013 pada umur $\geq 15$ Tahun sebesar $0,5 \%$ atau diperkirakan sekitar 883.447 orang, sedangkan berdasarkan diagnosis dokter/gejala sebesar 1,5\% atau diperkirakan sekitar 2.650.340 orang. Berdasarkan diagnosis/gejala, estimasi jumlah penderita penyakit jantung koroner terbanyak terdapat di Provinsi Jawa Timur sebanyak 375.127 orang $(1,3 \%)$, sedangkan jumlah penderita paling sedikit ditemukan di Provinsi Papua Barat, yaitu sebanyak 6.690 orang (1,2\%) (Kemenkes RI, 2014).

Pertolongan pertama yang tepat pada kasus henti jantung adalah bantuan hidup dasar (BHD). Tindakan yang bisa dilakukan adalah resusitasi jantung paru (RJP). Tujuan dari resusitasi jantung paru adalah mengembalikan sirkulasi spontan serta mempertahankan fungsi organ vital pada henti jantung dan henti nafas dengan melakukan kompresi dada dan bantuan nafas (Alga dkk, 2018). Alga dkk (2018) menyatakan bahwa pelatihan resusitasi jantung paru dapat meningkatkan pengetahuan siswa kelas $X$ di SMAN 1 Karanganom Klaten dengan ( $\mathrm{p}$ value $=0,000$ ).

Pondok pesantren Bayt Al Hikmah merupakan pondok pesantren kategori modern yang mengajarkan pendidikan umum di mana persentase ajarannya berimbang antara ilmu agama Islam dan ilmu umum. Para santri dibekali berbagai ilmu agama dan juga pengetahuan umum dan berbagai keterampilan agar dapat bermanfaat dalam kehidupan bermasyarakat. Pemberian pengetahuan dan keterampilan dalam menolong klien yang berada dalam kondisi gawat dan darurat merupakan hal yang sangat urgent untuk dimiliki oleh setiap santri agar dapat memberikan tindakan yang tepat dan akurat pada klien dilingkungan pondok maupun di masyarakat sekitarnya. Di pondok pesantren Bayt Al Hikmah, antara siswa laki-laki dan perempuan di bedakan lokasi gedung sekolahnya. Siswa dan Siswi SMA tidak satu gedung dan tidak satu kelas.

Tujuan dari kegiatan pengabdian masyarakat ini adalah santri dapat berperan aktif dan dapat memberikan pertolongan pertama henti jantung dan henti nafas secara tepat serta mampu melakukan RJP. Berdasarkan latar belakang tersebut, peneliti tertarik melakukan pendidikan kesehatan tentang bantuan hidup dasar pada santri di Pondok Pesantren Bayt Al Hikmah Kota Pasuruan Jawa Timur. 


\section{MASALAH}

Alasan kami memilih Pondok Pesantren Bayt Al Hikmah adalah santri berada di pondok selama 24 jam sedangkan pusat kesehatan pesantren buka tidak 24 jam, kegiatan santri yang padat dan asrama dengan 4 lantai tanpa lift. Fasilitas kesehatan seperti Puskesmas ataupun Rumah Sakit jarak membutuhkan waktu lebih dari 10 menit, sehingga ketika ada santri atau pengurus pondok yang mengalami henti jantung dan henti nafas sulit dipertahankan. Selain itu minimnya pengetahuan santri tentang bantuan hidup dasar.

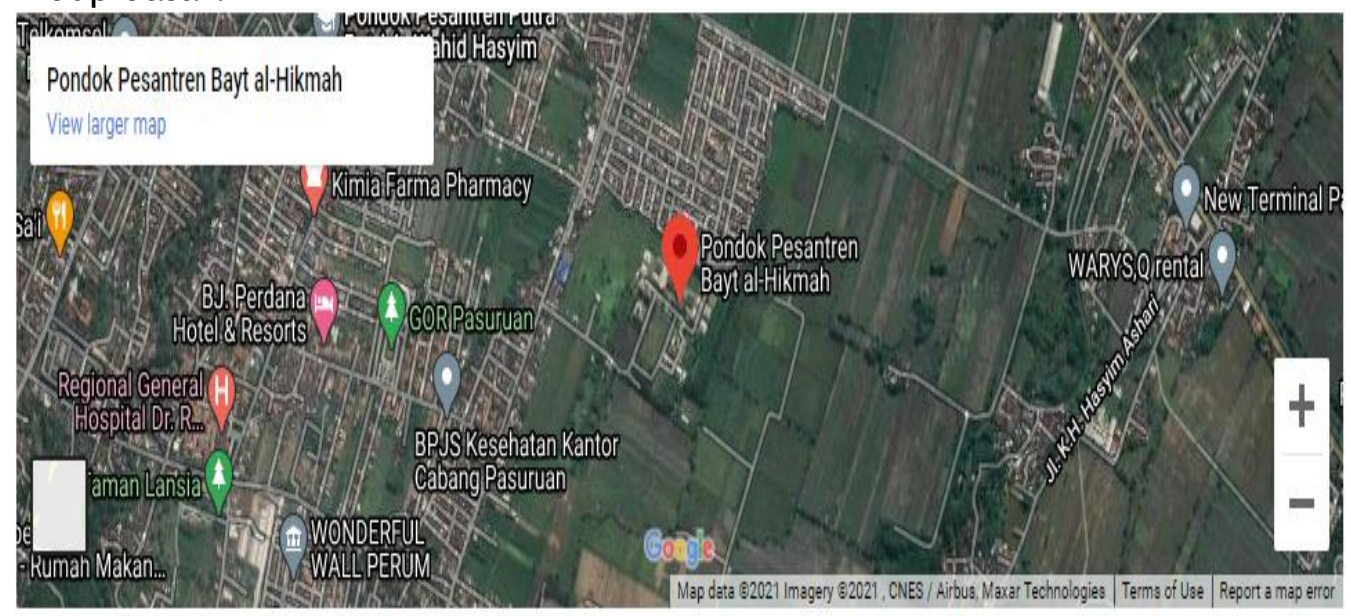

Gambar 2.1 Peta Lokasi Kegiatan

\section{METODE}

Kegiatan ini dilakukan metode pelatihan. Sebelum dimulai pelatihan terlebih dahulu dijelaskan maksud dan tujuan dilakukan kegiatan pelatihan. Dibuka oleh kepala pusat kesehatan pesantren, dilanjutkan dengan perkenalan dan penyampaian materi. Dalam pelaksanaan kegiatan ini menggunakan media LCD untuk pemaparan teori tentang sistem sirkulasi dan pernafasan dilanjutkan dengan diskusi terkait anatomi fisiologi sistem tersebut. Untuk hari kedua, dilakukan demonstrasi tentang ketrampilan RJP dan dilanjutkan dengan pendampingan latihan keterampilan RJP pada manekin.

\section{HASIL DAN PEMBAHASAN}

Kegiatan ini berlangsung selama 2 hari dan diikuti oleh siswi SMA dan SMK Bayt Al Hikmah Kelas X dan XI yang berjumlah 45 orang. Selama berlangsungnya kegiatan, peserta terlihat antusias mendengarkan dan aktif berdiskusi. Pada awal penyampaian materi, pemateri meminta peserta untuk menyampaikan pengetahuannya tentang sistem sirkulasi, pernafasan dan bantuan hidup dasar. Seminar dilaksanakan selama 5 jam penyampaian materi dengan diskusi dan praktek BHD selama 5 jam pada hari kedua dan setiap siswa memiliki kesempatan yang sama untuk melakukan RJP pada manekin. Hasil evaluasi sebagian besar santri (80\%) memahami dan mengerti tentang bantuan hidup dasar dan mampu mempraktekkan RJP kepada manekin meskipun masih butuh 
pendampingan Peserta senang dengan pelatihan ini, hal ini terbukti dengan banyaknya peserta yang aktif dalam diskusi dan mengajukan pertanyaan serta antuasia melakukan praktek pada manekin. Beikut gambar pelaksanaan kegiatan:
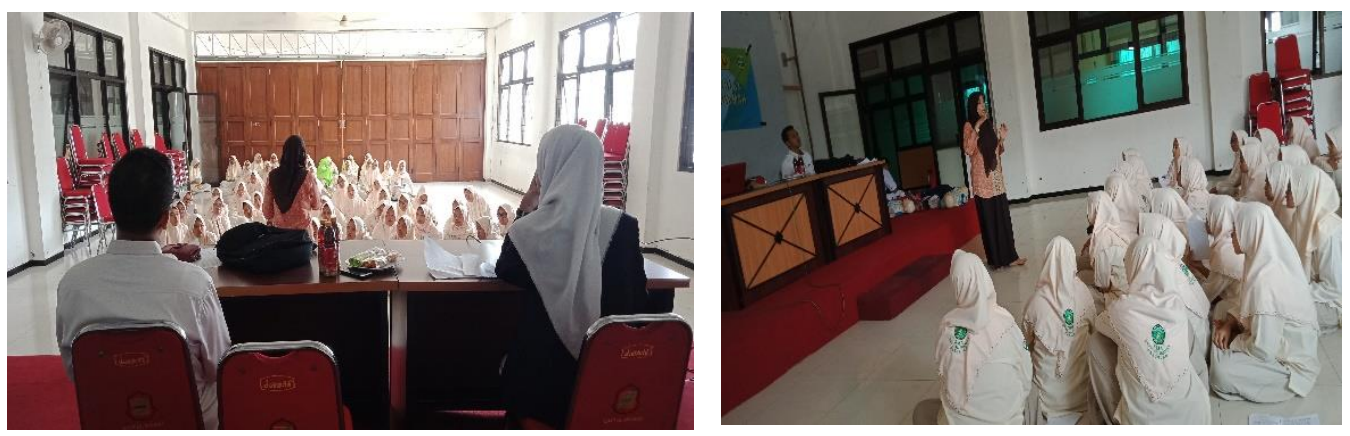

Gambar 4.1 Pembukaan Acara

Gambar 4.2 Penyampaian Materi
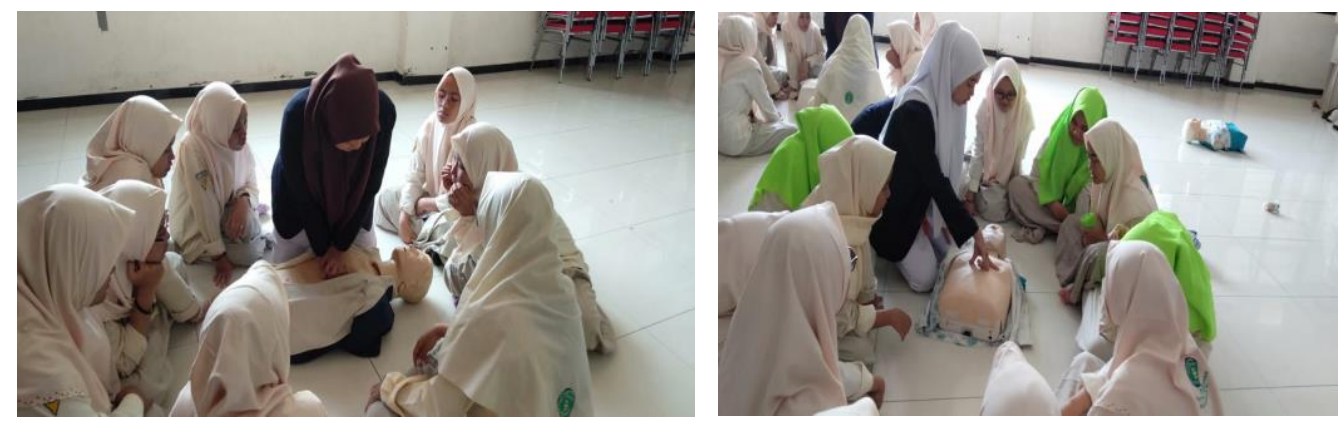

Gambar 4.4 Demontrasi RJP

Gambar 4.5 Demontrasi RJP
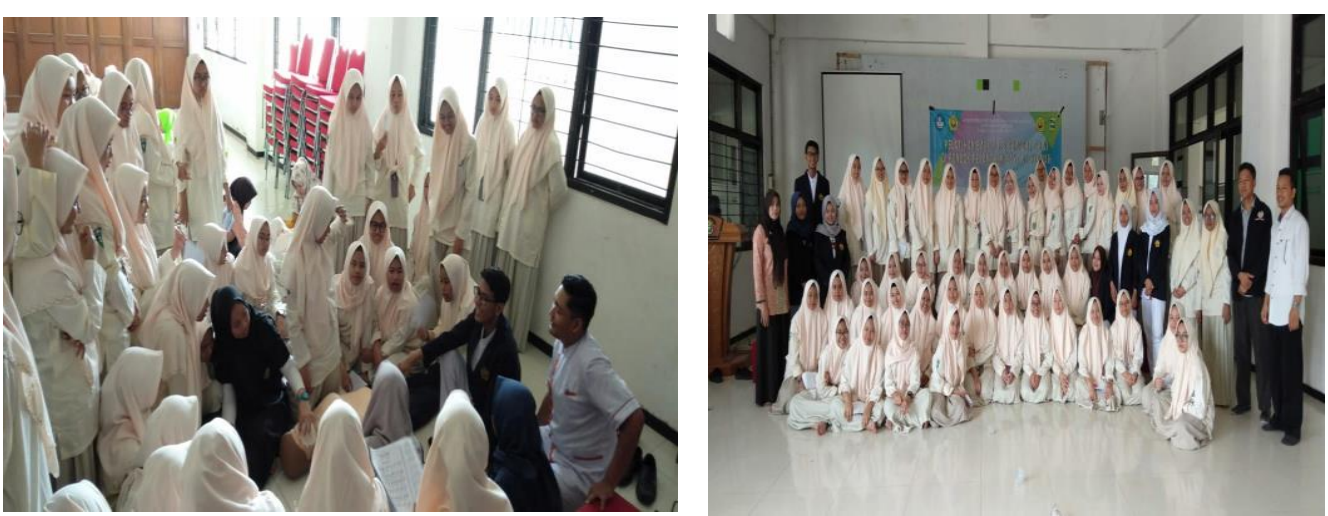

Gambar 4.5 Peserta Mempraktekkan RJP Gambar 4.6 Foto Bersama dengan

Peserta Pelatihan

\section{KESIMPULAN}

Kesimpulan yang bisa ditarik dari kegiatan ini seluruh santri aktif dalam kegiatan ini dan tidak meninggalkan tempat sampai acara selesai, hari kedua peserta masih antusias dan mau mencoba praktek satu persatu RJP. Perubahan peningkatan pengetahuan ketrampilan santri mengenai BHD di ukur dengan hasil apersepsi dan evaluasi terjadinya peningkatan pemahaman tentang bantuan hidup dasar serta mampu mempraktekkan cara melakukan RJP pada manekin. Dan jika ada temannya yang tidak sadar, santri akan menerapkan hasil pelatihan yang sudah diperoleh selama 2 hari. 


\section{DAFTAR PUSTAKA}

Alamsyah., Sulasri., Hasinda., \& Handayani, T. (2020). Familiarisasi Bantuan Hidup Dasar Bagi Orang Awam di Desa Romangloe Kecamatan Bontomarannu Kabupaten Gowa. Jurnal Kreativitas Pengabdian Kepada Masyarakat (PKM), 3(1), 39-45. doi: https://doi.org/10.33024/jkpm.v3i1.2487

Alga, F., Yuniar, I.F., \& Akbar, A.A. (2018). Pengaruh Pelatihan Resusitasi Jantung Paru (RJP) Terhadap Tingkat Pengetahuan Pada Siswa Kelas X Di SMAN 1 Karanganom Klaten. Persatuan Perawat Nasional Indonesia Jawa Tengah : Jurnal IImu Keperawatan Komunitas, 1(2), 31-37. doi: http: //dx.doi.org/10.32584/jikk.v1i2.304.

Alkatiri, J. (2007). Resusitasi Kardio Pulmonal dalam Sudoyo W Buku Ajar Ilmu Penyakit Dalam Jilid I Edisi IV. Jakarta : FKUI

Dianne, L. A., Allan, R.D., Stuart, B., Ricardo, A. S., Stephen, M. S., Benny, L. J., Blair, L. B., Dana, E. N., Jonathan, P. D., Elizabeth, A. H., \& Peter, A. M. (2018). Focused Update on Pediatric Basic Life Support and Cardiopulmonary Resuscitation Quality: An Update to the American Heart Association Guidelines for Cardiopulmonary Resuscitation and Emergency Cardiovascular Care. Circulation, 137(1), e1-e6. doi. https: //doi.org/10.1161/CIR.0000000000000540.

Hall, J. E. (2019). Buku Ajar Fisiologi Kedokteran Edisi 13. Jakarta: EGC Kemenkes, R.I. (2014). Situasi Kesehatan Jantung. Jakarta: Pusdatin.

Mark, S. L., Lauren, C. B., Peter, J. K., Henry, R. H., Erik, P. H., Vivek, K. M, Robert, W. N., Brian, J. O., James, H. P., Scott, M. S., Roger, D. W., Demetris, Y., \& Michael, W. D. (2015). Adult Advanced Cardiovascular Life Support. Circulation, 132(18), S444-S464. doi: https://doi.org/10.1161/CIR.0000000000000261.

Monica, E. K., Erin, E. B., Zachary, D. G., Robert A. S., Mark, T., Bentley, J. B., Raúl, J. G., Andrew, H. T., \& Thomas, R. (2015). Adult Basic Life Support and Cardiopulmonary Resuscitation Quality . Circulation, 132(18), S414-S435. doi: https://doi.org/10.1161/CIR.0000000000000259.

Muthmainnah. (2019). Hubungan Tingkat Pengetahuan Awam Khusus Tentang Bantuan Hidup Dasar Berdasarkan Karakteristik Usia Di RSUD X Hulu Sungai Selatan. Healthy-Mu Journal, 2(2), 31-35. doi: https: / /doi.org/10.35747/hmj.v2i2.235

PERKI. Henti Jantung. http://www.inaheart.org/education_for_patient/2015/5/7/henti_jantu ng\#: : text=Henti\%20jantung\%20adalah\%20hilangnya\%20fungsi,mencapai\% 20sekitar\%20300.000\%2D350.000\%20kejadian. (Diakses September 2, 2019). 